RU Сложные слова-окказионализмы: способы выявления идентификационных признаков

Гвоздева Е. В.

\begin{abstract}
Аннотация. Цель исследования - на материале композитной лексики определить признаки, релевантные для идентификации сложных слов-окказионализмов и неологизмов. Научная новизна заключается в том, что впервые к признакам окказиональности/потенциальности неолексики применены методы тестирования с целью выявления композитов, которые могут быть включены в толковые и аспектные словари. В результате показаны новые источники кодификации сложных слов группы потенциальной и окказиональной лексики, совпадающие по основным свойствам с неологизмами; определены признаки окказиональных и потенциальных единиц, которые актуальны и не актуальны на этапе появления слова; показано значение хронологии в кодификации слов потенциального характера; предложены оптимальные пути идентификации окказиональных слов.
\end{abstract}

\title{
Compound Nonce Words: Ways to Determine Identifying Features
}

\author{
Grozdeva E. V.
}

\begin{abstract}
The study aims to determine the features which are relevant for identification of compound nonce words and neologisms, using material of composite lexis. Scientific novelty of the work lies in the fact that for the first time testing methods are applied to features of occasionality/potentiality of neological lexis in order to identify composites which can be included into explanatory and specialised dictionaries. As a result, new sources of codification of compound words are shown - groups of potential and nonce lexis whose basic properties match those of neologisms; features of nonce and potential units, which are relevant or irrelevant during the word formation stage, are determined; significance of chronology in codification of potential words is demonstrated; the best possible ways of identifying nonce words are offered.
\end{abstract}

\section{Введение}

Актуальность темы исследования обусловлена обращением к композитам окказиональной семантики к материалу, в кодификации которого существует ряд нерешенных проблем. В отечественной лексикографии до сих пор не найден последовательный способ кодификации сложных слов, а в теории неологии (науки об изучении новых слов) дискуссионными остаются вопросы о статусе трех взаимосвязанных терминов: неологизмы, окказионализмы и потенциальная лексика.

Именно композиты - сложные слова, активно пополняющие словарный состав современного русского языка, находятся на стыке спорных вопросов неологии и практической лексикографии.

Важность кодификации сложных слов особенно проявляется в процессе обучения русскому языку как иностранному [5]. Сложные слова становятся главным показателем того, насколько динамично развивается язык с появлением электронной коммуникации и Интернета. Возрастает также потребность в дифференциации новой лексики и четких критериях идентификации сложных слов, так как сложные слова составляют бо́льшую часть новой и окказиональной лексики. На современном этапе развития языкознания ссылка на чутье исследователя не представляется достаточным научным аргументом, требуются более надежные критерии.

В связи с этим возникает также вопрос о тестировании существующих в науке принципов идентификации неолексики $[6 ; 9 ; 10 ; 15]$, насколько они применимы и эффективны в практической лексикографии.

Для достижения поставленной цели необходимо решить следующие задачи: 1) рассмотреть новые источники появления и фиксирования окказиональной и потенциальной композитной лексики; 2) выявить приоритетные для сложных слов признаки идентификации окказиональных слов и неологизмов; 3) с привлечением базы цитирования Национального корпуса русского языка (www.ruscorpora.ru, далее - НКРЯ) и поискового

Научная статья (original research article) | https://doi.org/10.30853/phil210023

(c) 2021 Авторы. ООО Издательство «Грамота» (๔ 2021 The Authors. GRAMOTA Publishers). Открытый доступ предоставляется на условиях лицензии СС BY 4.0 (open access article under the CC BY 4.0 license): https://creativecommons.org/licenses/by/4.0/ 
сервиса Яндекс (www.yandex.ru) в Интернете определить роль хронологии в кодификации окказиональных, инновационных и потенциальных единиц-композитов.

Практическая значимость. Результаты исследования могут использоваться в практике составления толковых словарей русского языка, словарей новых слов и окказионализмов. Кроме того, материалы статьи могут быть использованы в лингвистических вузах при изучении спецкурсов по теоретической и практической лексикологии и лексикографии, в процессе учебно-методической деятельности при создании учебных пособий по изучению неолексики.

Методы исследования. Лексико-семантический анализ применялся на этапе определения статуса исследуемых единиц. С помощью сравнительного компонентного анализа определялись структурно-семантические особенности окказионализмов. На этапе работы с системой НКРЯ использовались статистические методы.

Теоретической базой исследования послужили работы российских ученых в области словообразования, лексикологии и лексикографии: Е. А. Земской, В. В. Лопатина, И. С. Улуханова, И. П. Савицкого, А. Г. Лыкова, Е. Н. Ермаковой, Г. Н. Скляревской, Л. В. Алешиной и др.

Материалом исследования избрана композитная лексика разных стилевых пластов: инновации одного автора (сплошная выборка сложных слов из цикла рассказов В. П. Астафьева «Затеси») и окказиональная лексика из специальных словарей сложных слов и окказионализмов [3; 8; 11; 12]. При исследовании окказионального статуса композитов использовались данные толковых и аспектных словарей русского языка $[2 ; 7 ; 14 ; 16 ; 17]$.

\section{Источники появления и фиксирования окказиональной и потенциальной композитной лексики}

Несмотря на то, что сложные слова были зафиксированы еще в 1789 году «Словарем Академии Российской» и входили затем во все последующие издания, словарная фиксация сложных слов не всегда верно отражала их состав в языке. Каждый словарь вносил свои правила фиксации композитов [4] и свое видение сложного слова как объекта кодификации. К разночтениям в композитологии впоследствии добавились нерешенные вопросы неологии, связанные с дифференциацией понятий в ряду новых слов, в том числе сложных.

Составляя список новых слов для кодификации (разработки в словарях), лексикограф в первую очередь задается вопросом о реальности тех или иных слов-неологизмов, окказионализмов, авторских инноваций. Речь идет не только о новых словах, образованных по известным словообразовательным моделям, типа постнолищый [13], широкоштанный [1], собаколюбие [13] и т.п. (ср. модели-аналогии в русском языке: бел/о/лиц/ый, широк/о/пол/ый, человек/о/люб/ие), но и о таких авторских инновациях, как широкодушно [1], малонатоптанный [Там же], веснотворение [Там же], которые, на первый взгляд, тоже имеют аналоги в языке (ср., например, велик/о/душ/н/о, мало/хож/ен/ый, стих/о/твор/ени/е и т.п.). Однако аналогия здесь исключительно словообразовательная, а лексико-семантический статус композитов широкодушно, малонатоптанный, веснотворение - окказиональный.

Существует несколько основных путей пополнения и фиксации лексики сложными словами. Во-первых, это новая терминология. В язык могут привноситься сразу группы слов с одинаковыми морфемами и различными еще не устоявшимися вариантами написания (слитно и через дефис): нью-вейв, ньюскул, ньюслеттер, ньюсмейкер, ньюсрум, ньюфи, нью-эйдж и т.п.

Ньюсмейкер (англ. news - новости + make - делать) - человек, политический деятель, артист, спортсмен и т.д., который становится объектом внимания журналистов [3, с. 144]; ньюсрум (англ. news - новости + room - комната) - оснащённая новейшим оборудованием студия для производства информационных программ [Там же]; ньюфи (англ. new-fy) - перен. прижимистый, незадачливый человек - мишень многочисленных анекдотов и насмешек в Канаде [Там же]; нью-эйдж (англ. new age - букв. новая эра, эпоха) - возникшее на Западе во второй половине XX в. движение духовного возрождения [Там же] и т.п.

Появление новых денотатов в современной действительности создает еще один пласт лексики неологизмов-композитов, тоже терминологической, но образованной уже из компонентов (первых и вторых частей сложного слова), освоенных русским языком. Речь идет о компонентах композитов, которые по отдельности - как первые и вторые части сложных слов, а также как самостоятельные лексемы активно представлены в толковых словарях русского языка (водо..., гидро..., звуко..., мелко...; роллеры и т.п. [17]), но никогда ранее не сочетались друг с другом в пределах одного сложного слова. Ср., например: водозащита (1-1) [13] $\rightarrow$ водозащитный (10-24) [2, с. 140]; водопропуск (0) $\rightarrow$ водопропускной (16-36) [16, с. 149]; гидромассаж (9-14) [Там же, с. 221] $\rightarrow$ гидромассажный (19-30) [13]; звуковидение (3-5) [16, с. 386] $\rightarrow$ звуковизор (1-2) [Там же]; звукорежиссёр (75-110) [Там же] $\rightarrow$ звукорежиссура (0) [Там же]; лосевод (0) [Там же, с. 556] $\rightarrow$ лосеводство (0) [Там же], лосеводческий (0) [Там же]; лыжероллеры (1-1) [Там же, с. 559] $\rightarrow$ лыжероллерный (2-2) [13]; мелкотемье (27-34) [16, с. 589] $\rightarrow$ мелкотемный (2-2) [Там же] и т.п.

В круглых скобках указаны индексы встречаемости слова в базе НКРЯ, которые означают количество документов с данным словом и общее количество примеров (терминология НКРЯ). Данные индексы помогают судить об употребительности (условной частоте) слова в речи и узусе. Так, например, встречаемость в текстах НКРЯ сложных слов лосевод, лосеводство, лосеводческий сопровождается индексом «ноль», в то время как встречаемость в текстах популярного композита звукорежиссёр отмечена индексом 75-110.

Таким образом, база НКРЯ может дать первое представление о наличии слова в языке и речи; также она является одним из источников, по которому проверяется фиксация того или иного композита. Однако 
по индексу употребительности можно судить лишь о представленности той или иной лексемы в базе цитирования, но не о ее кодификации. Данные о кодификации получаем из толковых, орфографических и сводных словарей русской лексики. В приведенных выше примерах сведения о кодификации расположены в квадратных скобках. Как можем заметить, не все сложные слова представлены в словарях. По сведениям «Сводного словаря современной русской лексики» [Там же], на момент его выхода (1991 год) не имели кодификации композиты водозащита, водопропуск, гидромассажный, лыжероллерный. Сегодня, спустя 30 лет, эти сложные слова продолжают оставаться за рамками толковых словарей.

Еще один пласт новой композитной лексики находится в произведениях художественной литературы. Это так называемые авторские инновации, неологизмы, окказионализмы. К появлению авторской неолексики ведут поиски новых средств выражения, противодействие стандартизации, стертости, штампам в языке литературы. Художники создают новые слова, которые выполняют стилистическую функцию. Авторские окказионализмы, такие как веснотворение, солнцезарный, широкодушно, невзаправдашне и т.п. (например, у В. П. Астафьева) способствуют повышению образности, яркости и выразительности повествования:

По всему столу, на бумагах, на чернильнице, на окне лежит, светится цветочная пыльца, а сережки, отдав себя грядущему празднику веснотворения, как-то опустошенно обвиснут, свернутся и упадут отгорелыми папиросными бумажками (В. П. Астафьев. Сережки) [1]. Однажды на исходе января шел я малонатоптанной узкой тропой, вижу: поперек нее лежит ольха, из снега желтеет пенек с красной каемкой (В. П. Астафьев. Сережки) [Там же]. Непорочными, какими-то невзаправдашне театральными цветами были завешаны магнолии (В. П. Астафьев. Родные березы) [Там же]. В солнцезарный легкий день озеро чудилось таким приветливым, таким дружески распахнутым, будто век ждало оно нас, невиданных и дорогих гостей (В. П. Астафьев. Сережки) [Там же]. Садовник широкодушно высвободил место березам в этом тесном парке, где обязательно кто-то и кого-то хотел затмить, а потом и задушить (В. П. Астафьев. Родные березы) [Там же]. ...оболваненные ножницами пучки роз, возле которых так любят фотографироваться провинциальные дамочки и широкоштанные кавалеpы (В. П. Астафьев. Родные березы) [Там же]...

Существуют и другие пути появления неолексики, бо́льшая часть которой представляет собой окказиональное словотворчество в тех жанрах, где окказиональность выступает самоцелью, а сложные слова образуются в соответствии с установкой на игру, юмор и оценочность. Ср., например, композиты из «Словаря окказионализмов русского языка» [8] с приведенными выше авторскими инновациями В. П. Астафьева: алконавт (алкоголик + космонавт) [Там же, с. 14], астралопитек (астрал + австралопитек) [Там же, с. 15], бандитятко (бандит + дитятко) [Там же], бермуторно (Бермуды + муторно), снегопадаль (снегопад + падаль) [Там же, с. 200], стрекозёл (стрекоза + козёл) [Там же, с. 201], хрущобы (Хрущёв + трущобы) [Там же, с. 209], лохомотив («Локомотив» + лох) [Там же, с. 142], футболеутоляющее (футбол + болеутоляющее) [Там же, с. 143], клоунатик (клоун + лунатик) [Там же, с. 162], Ревизорро (ревизор + Зорро) [Там же] и т.п.

Следует отметить, что не только потенциальные слова имеют возможность со временем пополнить корпус узуальных слов, но и подобные окказионализмы, созданные в среде устной речи и предназначенные «для создания комического эффекта или снижения высокого стиля какого-либо слова или выражения» [21, с. 476], в исключительных случаях могут стать кодифицированными единицами. Так, например, изменение лексического статуса произошло у вышеприведенных композитов алконавт [8, с. 14; 17], стрекозёл [8, с. 201; 20] и хрущобы [8, с. 209; 17]. Данные слова-окказионализмы в настоящее время зафиксированы не только словарем окказионализмов 2019 года издания [8], но еще толковым и энциклопедическим словарями русского языка, что автоматически переводит их в разряд узуальной лексики.

\section{Актуальные признаки идентификации окказиональных слов-композитов и неологизмов}

Научные дискуссии ведутся вокруг противоречий, существующих в терминологии новых слов, в частности - вокруг понятия «потенциальное слово». Потенциальные слова относятся то к системе языка [6; 19], то к разряду окказионализмов [9; $15 ; 18]$. За то время, что идет дискуссия, в науке выработались основные принципы, с помощью которых появилась возможность дифференцировать неологизмы и окказионализмы, а также уточнить статус потенциальных слов.

Количество актуальных признаков, относящих новое слово к той или иной категории, разнится в зависимости от научной концепции автора: так, А. Г. Лыков обосновывает 9 признаков окказионализмов (принадлежность к речи, творимость или невоспроизводимость, словообразовательная производность, ненормативность, функциональная одноразовость, экспрессивность, номинативная факультативность, синхроннодиахронная диффузность, индивидуальная принадлежность) [10, с. 10-16], И. П. Савицкий выделяет 5 признаков окказионального слова (неузуальность, функциональная одноразовость, принадлежность к единицам речи, ненормативность, контекстуальная прикрепленность) [15, с. 155-158].

Далее рассмотрим, насколько признаки окказиональности применимы к разряду сложных слов и актуальны для практической лексикографии. Вслед за И. П. Савицким [Там же], В. В. Лопатиным [9] и И. С. Улухановым [18] мы придерживаемся точки зрения, что потенциальные слова и окказионализмы на первом этапе своего появления трудноразличимы и их дифференциация не столь актуальна. Те и другие группы слов можно считать окказиональными, с той лишь разницей, что потенциальная лексика имеет больше возможностей к кодификации. 
В первую очередь следует протестировать на окказиональность слова терминологического характера. С этой целью новые композиты проверяются на неэкспрессивность - главный критерий реальности слова, отличающий его от окказиональной лексики. Вторым проверочным признаком нового слова является способность к словопроизводству по активным словообразовательным моделям - это тоже свойство терминологической лексики. Ср., например:

Высоковольтник [16, с. 195], 1954: (1-1) Инженер-высоковольтник отозвался вполголоса: - Дыму много, а нажарено мало (Д. Гранин. Искатели) [13]. Газорезка [16, с. 206], 1988-1996: (1-1) У нас в очередной раз кончился кислород, встала газорезка (К. Серафимов. Записки спасателя) [13]. Газорезчик [16, с. 206], 1970-1975: (4-4) Я вообще-то электросварщик. И газорезчик тоже. Ремеслуха (О. Куваев. Территория) [13]. Газорезчица [16, с. 206], 2004: (1-1) К вечеру бригада газорезчищ срезала последние остатки поврежденной части моста (Не ошиблись в выборе // Профессионал. 2004. 29 сентября) [13] и т.п.

Как показывают цитатный материал и сведения о кодификации (ссылка на словари помещена сразу за словом в квадратных скобках), все слова-термины являются неологизмами и зафиксированы в орфографических словарях и словарях новой лексики. Логично предположить, что они должны отличаться от окказионализмов, таких, например, как водозащита, водопропуск, гидромассажный, лыжероллерный и т.п. по девяти $[10$, с. $10-16]$ или пяти основным признакам [15, с. 155-158]. Однако этого не происходит. Анализ показывает, что семантические, словообразовательные и дистрибутивные свойства приведенных групп композитов совпадают, и сложные слова отличаются лишь индексами НКРЯ.

Противоречие тем более очевидно, что неологизмы как часть узуальной системы приняты языком и должны регулярно воспроизводиться (так как называют новые реалии), а окказиональные слова как единицы речи имеют прямо противоположные признаки, они неузуальны и некодифицированы. На этапе появления нового слова, когда оно еще не отмечено словарями, как показывает исследование, отличительные признаки окказионализмов и неологизмов «не работают». Это важное свойство терминов окказионального характера.

Появление у слова семной активности (изменение значения) и производных слов увеличивает шансы на включение его в словари. Однако подобная активность может проявляться и у окказиональных образований. Ср., например, окказионализм мелкозвон у Ф. М. Достоевского и производный композит мелкозвонный у современного автора. Производное слово у композита зафиксировано в печатном источнике только через 120 лет:

1862: Кандалы мои были неформенные, кольчатые, «мелкозвон», как называли их арестанты (Ф. М. Достоевский. Записки из Мертвого дома) [13]; 1984: Мелкокудрявая, вечно встрёпанная, крутобокая, с ярким румянцем. Заразительный, мелкозвонный смех... Даша! При Даше всё становилось просто (И. Грекова. Фазан) [Там же].

Характерно и то, что в производном слове-окказионализме наблюдается изменение сочетаемости - сема звучания оказывается в сочетании с другим объектом (кандалы «мелкозвон», мелкозвонный смех). Этот случай не единственный, когда появление производных происходит через какой-то период времени, когда в языке в них возникает необходимость.

Как видим, многие композиты-окказионализмы не наделены признаками окказиональности в полной мере. Так, например, признак невоспроизводимости присущ далеко не всем окказионализмам: многие композиты неоднократно воспроизводятся в текстах, что подтверждают данные НКРЯ: гидромассажный (индекс НКРЯ 19-30) [Там же], мелкозвонный (индекс НКРЯ 2-2) [Там же] и т.п.; признаком ненормативности обладают далеко не все композиты, большинство из них образовано не по окказиональным, а по действующим активным моделям словообразования: пустоглазый, мелкозвонный и т.п.; функциональная одноразовость присуща также не всем окказионализмам - некоторые сложные слова не являются «функционально-одноразовыми» в НКРЯ их индекс встречаемости больше 1-1: широкоштанный (индекс НКРЯ 5-6) [Там же], широкоштанник индекс НКРЯ 5-6 [Там же]; признак экспрессивности отсутствует у окказиональных композитов терминологического характера, ср., например: водозащита, водопропуск, гидромассажный, лыжероллерный и т.п.

Более того, рассмотренные в статье окказиональные слова в той или иной степени демонстрируют полное или частичное совпадение со словами прямо противоположных групп - неологизмами и узуальной лексикой, что говорит о диффузности границ между разными группами сложных слов - окказионализмами, потенциальными словами и неологизмами.

Основные признаки, по которым однозначно вычленяются окказионализмы-композиты - это словообразовательная производность (что вполне очевидно для сложных слов, так как они являются производными априори) и контекстуальная прикрепленность, то есть неузнаваемость слова вне контекста и неотделимость контекста от композита. Это, как правило, окказионализмы - авторские инновации типа занудовлетворение (зануд/а + удовлетворение), смысл которых становится понятен только в родном и единственном контексте, для которого они и были созданы: Удивительное чудо не порадует зануду: Его стихотворения - занудовлетворение (Б. Волжанин) [8, с. 21].

Окказионализмы подобного рода, такие как землепроходимец [Там же], камазонки (КамАЗ+ амазонки) [Там же, с. 23], лжизнь (лживый + жизнь) [Там же, с. 25], долбожитель (долгожитель + долб/ить) [Там же, с. 74] и т.п. никогда не выходят за границы предложения, в котором они функционируют, а для понимания смысла сложного слова требуется более объемный контекст. Ср., например: В чем мы свирепо не нуждаемся. Любой гвоздь. Обломки кирпича. Отходы вашей пищебумажной продукции (М. Жванецкий. Удар с предоплатой); пищебумажный (пи/сч/е/бумажный + пища) [Там же, с. 188].

Неузнаваемость слова вне контекста и словообразовательная производность - это не только признаки окказиональных образований, но и своеобразные четкие маркеры, по которым окказионализм без труда 
опознается еще на этапе отбора лексики, что очень важно в лексикографической работе при составлении словника словаря. Окказионализмы, отвечающие признаку контекстуальной прикрепленности, как правило, соответствуют и всем остальным признакам окказиональности.

\section{Роль хронологии в кодификации окказиональной композитной лексики}

На примере композита беломошник рассмотрим хронологию появления слова в текстах и проследим за тем, как с течением времени меняется статус композита в словарях.

1942-1948: В борах-беломошниках и верещатниках типично предварительное возобновление сосной (С. Алексеев. Рубки в лесах севера) [13]; 1956-1957: - Так вот прямо идите... бор-беломошник кончится, сырь трава пойдет (В. А. Солоухин. Владимирские просёлки) [Там же]...; 1968-1991: С чистого места, с беломошника, с брусники глухарь крутанул назад (В. П. Астафьев. Последний поклон) [1]; 1973-1978: ...он выстлал ее плитами беломошника, который неподалеку нарезал лопатой (Ф. Абрамов. Дом) [13]; 1986: Боровой рыжик любит расти... в старых борах-беломошниках (В. Ф. Барашков. А как у вас говорят?) [Там же]...; 1990-1993: ...3аросшим лишайником, беломошником, вощаной брусникой (П. Алешковский. Жизнеописание Хорька) [Там же]; 1999: ...серые поросли беломошника (В. Быков. Волчья яма) [Там же].

По данным «Сводного словаря современной русской лексики», композит беломошник появился в 1984 году в словаре-справочнике «Новые слова и значения: по материалам прессы и литературы 70-х годов» [16, с. 78]. В 2000 году слово фиксируется толковым словарем Т. Ф. Ефремовой с расширенным значением (более узкое значение ‘белый мох’ заменяется семами 'светлый мох'): БЕЛОМОШНИК. Сосновый бор, растущий на почве, покрытой светлым мхом. Бор-беломошник [17]. В 1968 году у сложного слова беломошник, образованного от сочетания «белый мох», зафиксировано родственное слово беломошный (с теми же семантическими компонентами: ‘белый + мох’), а в 2004 году - еще один вариант - беломошниковый, который по всем признакам соответствует потенциальному слову, то есть будущему неологизму. Таким образом, за тридцать лет сформировалось лексическое гнездо из трех единиц композитов: беломошник, беломошный, беломошниковый:

1968: Возле беломошных болот били пестрого куропана, гоняли и путали молодых зайцев [1]. 2004: ...nирогенные беломошниково-брусничниковые сосняки Северного Зауралья веками сохраняли стабильность из-за специального выжигания напочвенного покрова. <...> Это выжигание проводилось мансийскими оленеводами каждые 20 лет. Таким образом обновлялись беломошниковые пастбища (Пожароустойчивость сосняков низменного Заволжья // Лесное хозяйство. 2004. 14 декабря) [13]; 2007: БЕЛОМОШНЫЙ, диал. Поросший белым мхом. Сидит он на переднем возке развалясь, что тебе беломошная кочка косматая, запорошенный снегом с ног до головы [7].

С момента печатной фиксации окказионального слова беломошник (1942 г. - по данным НКРЯ) до появления слова в словарях (1984 г. - [16]) слово изменило свой статус с окказионального на узуальный. Однако нельзя сказать, что данный композит претерпел какие-либо серьезные изменения в лексическом значении, в экспрессивности, сочетаемости, в словообразовательной активности и прочих признаках окказиональности. Скорее всего, данное слово изначально не имело свойств окказионализма.

И это очень важное наблюдение - не все слова-окказионализмы (то есть слова, не зафиксированные словарями) демонстрируют общепринятые свойства окказиональности. Более того, некодифицированное слово по своим признакам может быть неотличимо от узуального.

Примером того, что окказиональное слово может обладать всеми признаками потенциального и узуального, является композит пустоглазый. Это слово не зафиксировано ни толковыми, ни аспектными словарями, ни словарями новой лексики. Отсутствие в словарях должно свидетельствовать о неузуальности этого сложного прилагательного, о неупотребительности его в общелитературном языке. Однако в НКРЯ оно представлено очень высоким для окказионализмов индексом - 39-54 (39 документов, 54 вхождения):

1909: В халате и туфлях, мягкий и неслышный... сел в ногах, долго смотрел на пустоглазую голову неспавшего отца, на розовую, с белыми кружочками лампадку (С. Н. Сергеев-Ценский. Печаль полей) [13]; 1924-1925: Иногда он вздыхал: - Эх ты, пустоглазый (Максим Горький. Дело Артамоновых) [Там же]...; 1927: Кошка каким-то особенно тонким инстинктом поняла, что пустоглазая и безносая отошла от Колина изголовья, защелкав челюстями от злости (А. И. Куприн. Ю-ю) [Там же]; 1967-1989: Заталкивая в полевую сумку пачку писем и полотенце, Борис пустоглазо уставился на Мохнакова (В. П. Астафьев. Пастух и пастушка) [Там же]; 1974: Пустоглаза тоска, змея костна - цинга, люто голодное, люто холодное - миньте нас, киньте нас, уйдите на посолонь (В. П. Астафьев. Царь-рыба) [Там же]...; 1999: И на пути к Белозерску мы видели сплошь пустые, заросшие бурьяном деревни, пустоглазые церковки с сорванными дверьми (В. П. Астафьев. Затеси // Новый Мир) [Там же]... и т.д.

Композит пустоглазый, оставаясь фактически окказионализмом (некодифицированным элементом), обнаруживает признаки узуального слова. Тексты показывают, что не подтверждается его функциональная одноразовость, так как слово активно используется в 54 контекстах разными авторами в разные периоды времени на протяжении ста лет.

Не подтверждается также ненормативность данного окказионального композита, так как слово образовано по актуальной словообразовательной модели (A+N: темн/о/глаз/ый, светл/о/глаз/ый, кос/о/глаз/ый и т.п.). Контекстуальная прикрепленность тоже не является признаком данного слова - оно не зависит от контекста и обладает семной активностью и широкой дистрибуцией: пустоглазая тоска, церквушка; пустоглазая «Арктика»; пустоглазые дома, люди, головы, манекенщищы, парни, окна и т.п. (примеры взяты из НКРЯ). В дополнение 
ко всему у сложного слова в 1967 году зафиксирован дериват - пустоглазо [Там же], к которому композит пустоглазый выступает производящей базой, следуя всем правилам словообразовательной производности. Единственный признак, который отсылает данное слово к окказиональной лексике - это незафиксированность его словарями. Но этот признак нельзя считать релевантным, поскольку фиксируемость композитов словарями не имеет четких критериев.

\section{Заключение}

Проведя таким образом тестирование по актуальным признакам окказиональной, потенциальной и авторской инновационной лексики из различных стилевых источников (всего в исследовании проанализировано около 300 единиц), мы можем сделать следующие выводы.

1. Нерегулярное и непоследовательное отражение сложных слов в словарях сказывается на процессе кодификации новой композитной лексики. Общие отличительные признаки узуальной и окказиональной лексики не всегда корректно «работают» в сфере сложных слов, поэтому новым источником пополнения кодификационной лексики являются группы композитов окказиональной семантики, в том числе и потенциальные слова.

2. Приоритетными признаками, идентифицирующими окказиональную композитную лексику, являются неузнаваемость слова вне контекста и неотделимость контекста от композита. Окказионализмы, отвечающие признаку контекстуальной прикрепленности, соответствуют и всем остальным признакам окказиональности. Неактуальным признаком окказионализмов считаем нефиксированность слова словарями, так как множество композитов не кодифицировано изначально. Приоритетными признаками потенциальных сложных слов являются неэкспрессивность, словообразовательная активность и узнаваемость слов вне контекста.

3. С привлечением базы цитирования Национального корпуса русского языка и поисковых сервисов Интернета определена роль хронологии в кодификации окказиональных, инновационных и потенциальных единиц-композитов. Частотно-временные характеристики появления слова, которые ранее не учитывались в исследованиях окказиональной лексики, являются важной составляющей определения статуса композита.

Нашим исследованием доказано, что сложное слово может считаться потенциальным и иметь возможность фиксироваться словарями, если на протяжении значительного отрезка времени (сто и более лет) композит проявляет семантическую и словообразовательную активность, образован по продуктивной словообразовательной модели, его значение определяется носителями языка без контекста, а в базе НКРЯ слово представлено индексом более 1-1.

Перспективы дальнейшего исследования развития данной темы видим в подробном изучении признаков окказиональности на более объемном и разнообразном стилевом материале с учетом длительных хронологических данных. Результаты исследований в данном направлении помогут ввести корпус новой композитной лексики в толковые и аспектные словари, а также найти объяснение существующим противоречиям в терминах неолексики и решить многие задачи лексикографирования сложных слов.

\section{Список источников}

1. Астафьев В. П. Затеси [Электронный ресурс]. М.: Эксмо, 2008. URL: https://thelib.ru/books/astafev_viktor/ zatesi-read.html (дата обращения: 08.12.2020).

2. Большой толковый словарь русского языка: А - Я / сост. и гл. ред. С. А. Кузнецов; РАН, Ин-т лингв. исслед. СПб.: Норинт, 1998. 1535 с.

3. Габдреева Н. В., Гурчиани М. Т. Словарь композитов русского языка новейшего периода. М.: Флинта; Наука, 2012. 280 с.

4. Гвоздева Е. В. Особенности кодификации сложных слов в толковых и аспектных словарях // Филологические науки. Вопросы теории и практики. 2019. Т. 12. № 4. С. 159-163.

5. Гвоздева Е. В. Развитие языковой компетенции в процессе чтения публицистических текстов на занятиях по русскому языку как иностранному // Филологические науки. Вопросы теории и практики. 2019. Т. 12. № 3. С. 340-344.

6. Земская Е. А. Словообразование как деятельность. Изд-е 2-е, стер. М.: КомКнига; URSS, 2005. 224 с.

7. Историко-лингвистический словарь трилогии А. М. Бондаренко «Государева вотчина» [Электронный ресурс] / Сибир. федер. ун-т. Красноярск, 2007. URL: https://sovereign_patrimony.academic.ru/ (дата обращения: 03.12.2020).

8. Козинец С. Б. Словарь окказионализмов русского языка. М.: Флинта, 2019. 224 с.

9. Лопатин В. В. Рождение слова. Неологизмы и окказиональные образования. М.: Наука, 1973. 152 с.

10. Лыков А. Г. Современная русская лексикология (русское окказиональное слово). М.: Высшая школа, 1976.120 с.

11. Меркурьева Н. М. Словарь синонимов русского языка. Сложные слова. Около 400 синонимических рядов. К - О. М.: РЭУ им. Г. В. Плеханова, 2020. 186 с.

12. Меркурьева Н. М. Словарь синонимов русского языка. Сложные слова. Около 500 синонимических рядов. А - И. М.: РЭУ им. Г. В. Плеханова, 2018. 200 с.

13. Национальный корпус русского языка [Электронный ресурс]. URL: http://www.ruscorpora.ru (дата обращения: 03.01.2020). 
14. Русский орфографический словарь [Электронный ресурс] / РАН, Ин-т рус. яз. им. В. В. Виноградова; отв. ред. В. В. Лопатин. М.: Азбуковник, 1999. URL: https://opatin.academic.ru/ (дата обращения: 08.12.2020).

15. Савицкий И. П. Критерии идентификации окказиональной лексики (на материале немецких печатных СМИ) // Вестник Кемеровского государственного университета. 2014. № 1 (57): в 2-х ч. Ч. 2. С. 151-159.

16. Сводный словарь современной русской лексики: в 2-х т. / АН СССР, Ин-т рус. яз.; под ред. Р. П. Рогожниковой. М.: Рус. яз., 1991. Т. 1. А - О. 800 с.

17. Современный толковый словарь русского языка [Электронный ресурс] / под ред. Т. Ф. Ефремовой (2000). URL: https://dic.academic.ru/contents.nsf/efremova (дата обращения: 08.12.2020).

18. Улуханов И. С. Словообразовательная семантика в русском языке и принципы ее описания. М.: Наука, 1977. 256 с.

19. Ханпира Э. И. Окказиональные элементы в современной речи // Стилистические исследования: на материале современного русского языка. М.: Наука, 1972. С. 245-317.

20. Энциклопедический словарь крылатых слов и выражений [Электронный ресурс]. М.: Локид-Пресс, 2003. URL: https://dic.academic.ru/contents.nsf/dic_wingwords/ (дата обращения: 26.12.2020).

21. Янко-Триницкая Н. А. Словообразование в современном русском языке / РАН, Ин-т рус. яз. им. В. В. Виноградова. М.: Индрик, 2001. 504 с.

\section{Информация об авторах | Author information}

RU Гвоздева Елена Викторовна ${ }^{1}$, к. филол. н., доц.

${ }^{1}$ Российский экономический университет имени Г. В. Плеханова, г. Москва

EN Gvozdeva Elena Viktorovna ${ }^{1}, \mathrm{PhD}$

${ }^{1}$ Plekhanov Russian University of Economics, Moscow

1gvozdeva_15@mail.ru

\section{Информация о статье | About this article}

Дата поступления рукописи (received): 08.12.2020; опубликовано (published): 26.02.2021.

Ключевые слова (keywords): сложное слово; окказионализм; неологизм; потенциальные слова; кодификация; композит; compound word; nonce word; neologism; potential words; codification; composite. 